\title{
Transatlantica
}

Revue d'études américaines. American Studies Journal

\section{L'adolescence est-elle soluble dans l'enfance? Définitions et délimitations du public en littérature et culture de la jeunesse}

\section{Adrienne Boutang}

\section{OpenEdition}

\section{Journals}

Édition électronique

URL : https://journals.openedition.org/transatlantica/14527

DOI : 10.4000/transatlantica. 14527

ISSN : 1765-2766

Éditeur

Association française d'Etudes Américaines (AFEA)

Référence électronique

Adrienne Boutang, «L'adolescence est-elle soluble dans l'enfance? ?éfinitions et délimitations du public en littérature et culture de la jeunesse », Transatlantica [En ligne], 2 | 2019, mis en ligne le 01 août 2020, consulté le 01 février 2023. URL : http://journals.openedition.org/transatlantica/14527 DOI : https://doi.org/10.4000/transatlantica. 14527

Ce document a été généré automatiquement le 1 février 2023

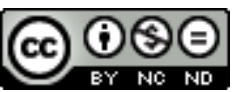

Creative Commons - Attribution - Pas d'Utilisation Commerciale - Pas de Modification 4.0 International - CC BY-NC-ND 4.0

https://creativecommons.org/licenses/by-nc-nd/4.0/ 


\title{
L'adolescence est-elle soluble dans l'enfance? Définitions et délimitations du public en littérature et culture de la jeunesse
}

\author{
Adrienne Boutang
}

1 Cet article est consacré à la difficile distinction entre enfance et adolescence au sein du public jeunesse. Comme on va le voir, la séparation entre ces deux catégories voisines est à la fois présente implicitement dans l'esprit du public et des producteurs d'objets culturels, et paradoxalement peu envisagée par les spécialistes de la culture de la jeunesse et de l'enfance. Les recherches sur le jeune public oscillent entre deux attitudes extrêmes. La première consiste à nier la différence entre ces deux publics et à faire de l'adolescence une sous-catégorie de l'enfance. La seconde insiste au contraire sur la séparation radicale entre ces deux phases de développement. Notre réflexion croise, sans s'y réduire, des enjeux liés au problème de la double adresse (crosswriting), c'est-à-dire le fait que certaines œuvres visent ou atteignent simultanément plusieurs catégories de publics, en l'occurrence plusieurs tranches d'âge. Notre hypothèse est que, bien que la double adresse soit au cœur de nombreuses réflexions contemporaines sur la culture de jeunesse, tout un pan de la culture destinée aux jeunes adultes obéit à une logique de segmentation exactement inverse.

2 L'article traitera conjointement des différents médias (littérature, films et séries télévisées) composant la culture jeunesse, qui a pris, dès son émergence après 1945 aux États-Unis, une forme transmédiatique (Doherty 165), comme l'indique la fréquence des adaptations cinématographiques ou télévisuelles de romans pour la jeunesse. Il y a continuité et échanges entre la littérature pour la jeunesse et les récits filmiques et audiovisuels. Tout d'abord parce que dans le contexte transmédiatique propre à la culture de masse et à la culture pour la jeunesse en particulier, la circulation des livres aux films (ou, plus tard, aux séries télévisées) s'est faite presque systématiquement par le biais d'adaptations, suivant une logique qui va des ouvrages de Susan Hinton à 
Hunger Games. Ensuite, parce que c'est bien dans les romans pour la jeunesse, notamment des bestsellers comme Seventeenth Summer, que les produits audiovisuels pour adolescents vont puiser des motifs, des schémas narratifs et une répartition en genres distincts (de la bluette au récit d'aventures). Nos exemples sont puisés dans un corpus qui part des premiers romans pour adolescents parus dans les années 1940 aux États-Unis, pour traverser l'histoire des teen movies et des teen series produits depuis les années 1950 jusqu'à la période contemporaine. Ces œuvres ciblant spécifiquement un public adolescent seront mises en regard d'un type de productions qui, comme nous le montrerons, visent pour leur part un public familial et sont reçues comme telles par les spectateurs. Un intérêt tout particulier sera, de ce point de vue, accordé au genre fantastique, plus spécifiquement à la fantasy et aux récits d'aventure qu'on peut considérer comme les genres intergénérationnels par excellence. Notre propos prendra souvent comme points de comparaison des œuvres réalisées ou scénarisées par Steven Spielberg, dont certains des films les plus célèbres nous semblent constituer le modèle même du récit familial.

3 En ouverture, afin d'exposer les enjeux de notre réflexion, citons le titre d'un commentaire paru sur Common Sense Media, site web nord-américain destiné à éclairer les parents sur ce qui convient ou non à un visionnage dit «familial ", à propos de la série fantastique Stranger Things (Netflix, Matt et Ross Duffer, 2016-), et qui manifeste précisément les limites de l'intergénérationnel : "A super good family show for teens! » (« Parent reviews »). Ce titre en forme de clin d'œil est en fait paradoxal, voire contradictoire : comme le montrent tous les commentaires qui suivent, l'objet même du débat est précisément de déterminer si l'émission est familiale ou bien si elle est destinée aux adolescents. La question n'est pas de savoir si, au sein de cette famille réunie, les parents pourraient être intéressés par la série, mais si cette dernière peut convenir à des enfants. La double adresse, c'est-à-dire l'idée qu'une œuvre puisse cibler à la fois adultes et enfants, est considérée comme allant de soi. Les interrogations et les inquiétudes portent sur le point séparant l'enfance de l'adolescence et, plus précisément, sur ce qui fait qu'une œuvre est inadaptée pour un public d'enfants.

Sociologues et historiens de la culture ont établi le caractère construit de l'adolescence. Selon Olivier Galland, « dans les sociétés primitives, on ne distingue qu'entre l'enfance et l'âge adulte, l'adolescence n'étant que la très courte transition, organisée autour des rites de passage, entre ces deux états » (Galland 5). Les avis divergent sur la datation exacte de cette prise de conscience d'une étape intermédiaire entre enfance et âge adulte. Pour certains, elle a émergé dans les classes bourgeoises entre le XVIII ${ }^{\mathrm{e}}$ siècle et la période victorienne en Grande-Bretagne (Cart 4-10) ; pour d'autres, c'est aux ÉtatsUnis à la fin de la guerre de Sécession, ou au tournant du $\mathrm{xx}^{\mathrm{e}}$ siècle, ou encore dans les années 1920. L'émergence du concept est jalonnée de quelques repères théoriques, telle la parution en 1904 des travaux du psychologue G. Stanley Hall. L'étape importante, dans notre perspective, est l'émergence de l'adolescent comme public ciblé par les industries culturelles. Les historiens de la culture la situent généralement autour de la fin de la Seconde Guerre mondiale aux États-Unis, quand apparaît une culture jeunesse conçue pour les adolescents, notamment le teen pic ou film pour ados (Shary ; Doherty), puis à la fin des années 1950, avec la création de la catégorie young adult dans les bibliothèques américaines. Si l'adolescent a émergé progressivement dans l'imaginaire culturel occidental, la question de la frontière le séparant du public enfantin demeure ambiguë, tout comme la délimitation chronologique de l'adolescence - souvent plus 
restreinte que la fourchette théorique de douze à dix-huit ans. Cet article revient sur ces différentes conceptions, tout en retraçant la manière dont une délimitation a par ailleurs été établie par les industries culturelles et les spectateurs. En effet, il importe de distinguer les délimitations entre enfance et adolescence établies, d'une part, au terme de recherches théoriques menées par des spécialistes de psychologie et, d'autre part, celles qui résultent de considérations, voire d'intuitions plus pragmatiques et sont guidées par la logique purement économique des producteurs des industries culturelles. L'objectif de cette réflexion n'est pas d'apporter une réponse définitive, mais d'exposer les enjeux de ces ambiguïtés dans le domaine de la culture de masse, particulièrement en Amérique du Nord où la culture adolescente populaire (teen culture) a émergé avant de se mondialiser. On croisera, tout au long de ce texte, des éléments appartenant à la réception par le grand public, à la terminologie savante et universitaire, et à l'étude des œuvres elles-mêmes - sans oublier les stratégies de ciblage de publics de niche par les industries culturelles.

\section{Quand l'adolescent disparaît derrière l'enfant : de la confusion terminologique à la panique morale, enjeux idéologiques}

5 Revenons dans un premier temps sur la confusion souvent manifeste entre l'enfant et l'adolescent. Si la distinction a été pensée par la sociologie et la psychologie, les analyses consacrées à la culture jeunesse, notamment à la littérature de jeunesse, se sont souvent focalisées sur l'opposition entre adultes et enfants, laissant partiellement de côté la distinction entre les deux catégories, plus mitoyennes, de l'enfance et de l'adolescence. L'inclusion même d'études consacrées aux adolescents dans des ouvrages sur l'enfance - qu'atteste d'ailleurs le présent article - manifeste cette difficulté à penser la différence entre les deux catégories.

6 En dépit des efforts des psychologues, sociologues et spécialistes des industries culturelles pour distinguer, au moins depuis les années 1960, l'enfance de l'adolescence, deux types d'ouvrages persistent à associer, voire à confondre ces deux phases: les manuels de psychologie pratique destinés aux parents, d'une part, et les textes de chercheurs travaillant sur la culture jeunesse, de l'autre, comme le montre une recherche lexicale organisée autour du syntagme « adolescents et enfants » réalisée sur un corpus d'ouvrages parus entre les années 1980 et les années $2000^{1}$. On constate que les auteurs qui s'intéressent à la culture de l'enfance (souvent synonyme de la culture jeunesse dans les ouvrages académiques) dans la littérature ou les médias audiovisuels ont tendance à gommer la catégorie de l'adolescence dans sa singularité, pour en faire une sous-catégorie de l'enfance. C'est particulièrement vrai des chercheurs qui, depuis les années 1990, ont focalisé leurs études sur les phénomènes de lecture ou de visionnage intergénérationnels.

7 Lorsque les deux catégories sont rabattues l'une sur l'autre, c'est donc souvent l'adolescent qui est éclipsé par l'enfant. La notion importante mobilisée implicitement par les théoriciens est celle de la double adresse (crosswriting). Paradoxalement, les études consacrées aux stratégies de ciblage simultané de plusieurs publics prennent peu en compte la spécificité de ce spectateur intermédiaire qu'est l'adolescent, mais se concentrent sur la binarité entre les lectorats adulte et enfant. La notion d'adolescence 
est alors mentionnée, mais rapidement laissée de côté. Maria Nikolajeva définit «la littérature et la culture de l'enfance » comme « englobant la période qui va de l'enfance jusqu'à la fin de l'adolescence » (Ix). Mais une fois cette spécificité relevée, l'autrice se concentre exclusivement sur l'opposition entre adulte et enfant, par exemple lorsqu'elle définit la double adresse comme la capacité des écrivains à "cibler ou posséder » un « lectorat double, constitué d'enfants et d'adultes » (Ix).

analyses de la double adresse ont ainsi tendance à brouiller ou à éclipser la différence entre enfance et adolescence qui, même lorsqu'elle apparaît au gré de l'analyse d'une œuvre, n'est toujours mentionnée que rapidement. Ainsi, dans Poetics of Children Literature, Zohar Shavit compare le style d'Enid Blyton à celui de la série Nancy Drew. Les deux œuvres, d'après Shavit, se rejoignent dans leur utilisation d'un vocabulaire et d'une syntaxe "simples ». Cependant, si l'on trouve chez Blyton nombre de "mots dont la fonction stylistique est de faire référence au monde de l'enfance ", Shavit affirme qu'il n'existe "aucune trace d'utilisation de ce type de phrases exclamatives » dans la série Nancy Drew. Cette divergence s'explique, selon Shavit, par «l'âge de l'héroïne (il s'agit d'adolescentes et non d'enfants)». La distinction entre enfance et adolescence est donc bien perçue et posée par l'autrice, mais rapidement laissée de côté, reléguée en parenthèse explicative, et Shavit revient à son axe principal, l'opposition entre les publics enfant et adulte, pour conclure que "par l'utilisation de ces techniques, Blyton et Keene effectuent une séparation physique entre adultes et enfants » (Shavit 106).

Les chercheurs en littérature ne sont pas les seuls à étudier conjointement des œuvres s'adressant simultanément à plusieurs tranches d'âge et à se pencher sur la dissolution de l'adolescence dans l'enfance. La question de la double adresse intéresse également les chercheurs travaillant plus largement sur la culture de masse. Ainsi, dans un texte célèbre consacré à la réception nostalgique, Fredric Jameson oppose, d'un côté, des « enfants et adolescents » qui « peuvent prendre ces aventures au pied de la lettre » et, de l'autre, un " public adulte qui est à même de combler un désir plus profond et plus nostalgique de revenir à une période plus ancienne et d'en revivre les étranges artefacts esthétiques » (Jameson 8). Or cette assimilation entre enfance et adolescence se fait dans une étude qui vise précisément à dissocier les réceptions en fonction de l'âge. S'il est vrai qu'adultes et adolescents ne sauraient faire l'expérience de la même «nostalgie » face à une période que certains ont connue et d'autres non, la distinction entre lectures au premier degré et au second degré est plutôt l'un des points de divergence entre enfance et adolescence. C'est d'ailleurs ce qu'a montré, dans les années 1980 et 1990, le virage ironique du genre de l'horreur adolescente, de la franchise Freddy qui s'est ouverte avec A Nightmare on Elm Street (New Line Cinema, Wes Craven, 1984) à la série des Scream (Woods Entertainment/Dimension Films, Wes Craven, 1996). Dans ce contexte, il n'est pas anodin que l'auteur ait choisi le genre de l'aventure pour illustrer son propos. Le récit d'aventure et sa modulation moderne, la fantasy, sont l'exemple même d'un genre susceptible de séduire à la fois les enfants et les adultes, et par conséquent un modèle parfait d'œuvre dite «familiale » - à condition précisément qu'en aient été exclus les traits qui, comme on le verra plus loin, ont vocation à séduire la tranche du public située entre ces deux catégories: les adolescents. La récurrence du syntagme «enfants et adolescents " sous la plume des spécialistes de la culture jeunesse, notamment des productions susceptibles de faire l'objet d'un intérêt intergénérationnel, nous semble donc manifester un déni de la 
singularité du public adolescent et une méconnaissance des différences fondamentales qui le distinguent du public enfantin.

Paraphrasant la définition du genre littéraire de la fantasy formulée par Mike Ashley (184), Gary Westfahl mentionne les deux tranches d'âge, enfance et adolescence, sans vraiment les distinguer l'une de l'autre. Selon lui, en effet,

les récits d'horreur ont pour caractéristique de comporter des enfants ou des adolescents qui affrontent une puissance maléfique et parviennent à la vaincre ou bien y succombent sans mûrir, tandis que les histoires appartenant à la fantasy ont pour caractéristique de comporter des enfants ou des adolescents qui affrontent une puissance maléfique et mûrissent pour devenir des adultes victorieux dans leur combat. (Slusser et Westfahl x ; c'est moi qui souligne)

Or chez Ashley, cette absence de distinction entre les deux catégories s'articule à la présence d'un motif initiatique : «la plupart des romans de fantasy sont structurés autour de quêtes [...] et c'est une stratégie naturelle que de figurer le rite de passage vers la pleine maîtrise de soi comme passage de l'enfance ou de l'adolescence vers l'état d'adulte » (Ashley 184 cité par Slusser et Westfahl x). Il est intéressant qu'Ashley mette au même niveau l'enfance et l'adolescence à l'occasion d'une distinction entre la fantasy et l'horreur. Ces deux genres, aux fonctionnements très différents, ne ciblent pas la même catégorie de public. On pourrait même considérer qu'ils manifestent nettement la différence entre deux publics bien identifiables. La fantasy vise l'enfance, sans bien entendu s'y restreindre puisqu'elle constitue, on l'a vu, le genre crossover par excellence. L'horreur cible plutôt, en revanche, un public adolescent (Derry 22).

11 Dans un article consacré à Steven Spielberg, Douglas Brode évoque la «préoccupation récurrente [du cinéaste] pour des enjeux liés à l'enfance et le fait que beaucoup de ses films comportent des enfants ou des adolescents dans les rôles principaux » (c'est moi qui souligne). Brode cite «Barry dans Rencontres du troisième type, Elliot dans E.T., Short Round dans Indiana Jones et le temple maudit, et Jim dans Empire du soleil » (327). Les trois premiers personnages appartiennent sans le moindre doute à l'enfance, le dernier seulement étant à la frontière entre enfance et adolescence, puisqu'il a douze ans. $\mathrm{Si}$ justifiée qu'elle soit par les préoccupations du cinéaste étudié - Spielberg, on y reviendra, ne s'intéresse guère à la parenthèse adolescente - l'assimilation de l'adolescent à la catégorie générale de l'enfance est ici manifeste. Elle reflète une tendance plus générale, chez les critiques comme chez les théoriciens de la culture populaire, à nier ou à minimiser la distinction entre le statut des enfants et celui des adolescents, distinction pourtant largement admise depuis les travaux fondateurs de Timothy Shary ou David Considine sur la culture adolescente ${ }^{2}$.

Cette tendance à rabattre la catégorie de l'adolescence sur celle de l'enfance peut tout d'abord s'expliquer, notamment pour le corpus antérieur aux années 1940, par les œuvres elles-mêmes. Celles-ci traitent souvent tous leurs personnages non encore adultes comme des enfants, même s'ils sont adolescents selon les critères établis par les psychologues. Gary Westfahl souligne ainsi que les Hardy Boys, souvent cités comme de bons exemples de l'émergence d'une culture adolescente populaire, se rattachent en réalité à la littérature pour enfants, en dépit de l'âge annoncé des héros. "Comme d'autres personnages de la littérature pour enfants, l'âge mental des Hardy Boys est très différent de leur âge biologique. Ils sont censés avoir dix-sept et dix-huit ans, mais ils pensent comme des enfants de neuf et dix ans " (Westfahl 30). De même, le fait que les critiques décrivent comme des enfants tous les personnages de Steven Spielberg qui ne sont pas encore adultes reflète probablement une tendance propre au cinéaste lui- 
même: représenter comme des enfants les personnages d'adolescents, y compris lorsqu'ils sont plus âgés, voire presque devenus adultes.

Cette confusion entre les deux catégories peut également être interprétée comme une stratégie idéologique, plus ou moins consciente, accompagnant une logique souvent conservatrice qui reflète la méfiance de la société envers sa jeunesse, notamment sous la plume des partisans de la censure. Il n'est donc pas étonnant qu'on la retrouve, par exemple, dans des textes qui s'insurgent contre le pouvoir excessif - ou jugé tel accordé à la jeunesse. Ainsi, dans un article au titre évocateur, «The Triumph of TeenProp ", très critique à l'égard de la culture jeunesse développée au $\mathrm{xx}^{\mathrm{e}}$ siècle dans la société occidentale, Gary Kern fustige « la nouvelle relation entre adultes et enfants qui a commencé après la Seconde Guerre mondiale et au cours de laquelle les adultes ont projeté sur les enfants, en particulier les adolescents, des qualités et des aptitudes que les adultes n'auraient jamais songé à attribuer aux enfants auparavant » (Kern 49-50 ; c'est moi qui souligne).

David Oswell rappelle que, dès le XIX ${ }^{e}$ siècle, les jeunes, au sens large, ont été envisagés comme des individus à la fois en danger et dangereux (Oswell 38), et l'image de leur dangerosité supposée s'est amplifiée dans la période contemporaine. «La décennie de la découverte des dangers menaçant l'enfance est devenue celle des enfants dangereux » (Campbell et Dawson 31, citées par Oswell 38). Dans cette perspective, les catégories de jeune (youth) et d'enfant sont mobilisées alternativement au gré des considérations politiques et idéologiques. Comme l'écrit Oswell, il arrive ainsi que, sous l'influence d'instances sociales conservatrices ayant pour objectif de contrôler les productions destinées à la jeunesse, les «jeunes gens [soient] construits comme des "enfants", vulnérables et crédules, ce qui constitue une légitimation efficace du pouvoir et du contrôle des adultes ». À l'inverse, « la catégorie "jeunes" est mobilisée lorsqu'on estime que les jeunes en question ne se comportent plus d'une manière convenable pour un enfant. La jeunesse renvoie à un moment de dérapage: un espace entre deux» (Oswell 37).

Oswell évoque ici la panique morale, c'est-à-dire l'inquiétude suscitée par l'émergence d'une culture organisée pour et autour des jeunes, tout particulièrement associée à la notion voisine de délinquance juvénile (Pearson). Par-delà ce rappel, on peut retenir que la délimitation entre les territoires respectifs de l'enfance et de l'adolescence ne dépend pas seulement de l'âge des personnages, mais aussi de la place qui leur est assignée dans la société et, en l'occurrence, dans les récits. S'il arrive que de tout petits enfants soient qualifiés de "jeunes » dès lors qu'ils se comportent de manière jugée inadaptée, on trouve, à l'inverse, des récits qui gomment les caractéristiques adolescentes d'un personnage pour l'intégrer dans un récit destiné à un public familial. C'est aux caractéristiques de ces œuvres tous publics, susceptibles d'être regardées par tous les membres de la famille indistinctement, à la différence des œuvres pour adolescents, que l'on va à présent s'intéresser.

\section{Délimitation de territoires}

Notre hypothèse est que loin de s'être rapprochées, comme le laisserait penser la littérature consacrée au crossover, les œuvres destinées à l'adolescence et les œuvres familiales ont eu tendance à se dissocier de manière croissante, la culture adolescente populaire étant l'exemple même d'un marketing de différenciation par ciblage d'un 
public de niche. Précisons tout d'abord pour quelle raison on a pu considérer que, dans la culture contemporaine, les sphères de l'adolescence et de l'enfance se rapprochaient au point de se confondre. Nous laisserons pour le moment de côté le phénomène sociologique spécifique de la pré-adolescence qui a, en anglais, conduit à l'invention du néologisme «tween » (Mitchell et Reid-Walsh ; Driscoll ; MacDonald).

Le premier trait qui peut donner l'impression d'un rapprochement entre les œuvres culturelles destinées à l'enfance et celles qui s'adressent aux adolescents est la tendance des premières à s'approprier un large spectre de sujets que l'on aurait tendance à exclure du champ de la littérature destinée à la jeunesse (Corr). Mais en réalité, la souffrance, le deuil et la violence font pleinement partie du canon de la littérature destinée aux enfants et aux pré-adolescents. La tendance de certains auteurs à traiter des thématiques sombres est d'ailleurs si marquée qu'elle a récemment fait l'objet d'articles indignés protestant contre ce goût macabre pour la «sicklit " (littérature malade) mettant en scène de jeunes personnages au bord de la mort (Carey). Dans le domaine cinématographique, on peut d'ailleurs considérer que l'invention aux États-Unis, dans les années 1990, à la suite de débats suscités par la violence jugée excessive du film Indiana Jones de Steven Spielberg (Paramount, 1984), de la catégorie PG-13 autorisant certaines représentations aux pré-adolescents de treize ans a marqué la reconnaissance d'une catégorie intermédiaire entre l'enfant et l'adolescent (Brode 328-329). Cette catégorie de public est jugée capable, comme les héros fictifs de fantasy, d'affronter une certaine quantité de violence et des enjeux adultes, mais reste interdite d'accès à ce qui relève de la sexualité et d'une violence se rapprochant du gore et mobilisant plus directement le corps. Ainsi, les films clés des teen movies, notamment la comédie scabreuse American Pie (Universal, Paul et Chris Weitz, 1999) et le film d'horreur Scream, ont reçu, de l'agence de classification des films (CARA), un classement R, catégorie plus restrictive que PG-13 puisqu'elle n'autorise l'accès des spectateurs de moins de dix-sept ans que s'ils sont accompagnés d'un adulte.

Outre la présence de ces thématiques adultes, le deuxième trait qui a pu donner l'impression d'une convergence entre œuvres pour enfants et pour adolescents est que de nombreuses fictions pour enfants représentent des conflits avec l'autorité. Selon Gary Westfahl,

[si les personnages] des livres classiques comme The Swiss Family Robinson et Mary Poppins acceptaient souvent de suivre les règles énoncées par leurs parents ou par des figures d'autorité, les jeunes protagonistes des séries fictionnelles désirent ardemment prendre les rênes de leur existence ; ils sont irrités par les restrictions que leur imposent des figures d'autorité plus âgées, exigent respectueusement plus de liberté et tentent de résoudre des mystères ou de parvenir au succès entièrement par leurs propres moyens. (Westfahl 39)

Par contraste avec la littérature enfantine classique du $\mathrm{XIX}^{\mathrm{e}}$ siècle et du début du $\mathrm{xx}^{\mathrm{e}}$ siècle, les enfants des séries plus récentes analysées par Westfahl, telle Chair de poule (Goosebumps) publiée entre 1992 et 1997 (Stine), revendiquent des caractéristiques communément attribuées plutôt aux adolescents.

La littérature pour enfants représente de manière récurrente ce fantasme, sans doute intrinsèquement lié à l'enfance : le détachement complet de la sphère familiale et de l'autorité adulte. Les personnages enfantins de ces fictions oscillent ainsi entre deux états extrêmes, l'impuissance et la maîtrise complète (Rabkin 3). C'est le schéma que l'on retrouve, par exemple, dans le célèbre Monde de Narnia (The Chronicles of Narnia) de CS Lewis, publié entre 1950 et 1956, dont les personnages passent directement de 
l'enfance à l'âge adulte lorsqu'ils intègrent l'univers fantastique. Loin de les rapprocher des récits adolescents, l'oscillation entre vulnérabilité et toute-puissance peut donc être pensée comme un trait caractéristique de la culture pour enfant, là où la culture de jeunesse met plutôt l'accent sur les troubles transitionnels. Les teen movies grand public sont conçus autour de personnages qui se cherchent, tentent de définir leur identité et de la mettre à l'épreuve auprès de leurs pairs, tâtonnant dans le bouleversement pubertaire : en somme, ces films explorent la fragilité d'individus en chantier (Boutang et Sauvage 24).

Les fictions pour et sur des enfants construisent souvent, surtout lorsqu'elles sont fantastiques, des univers dont parents et adultes sont absents ou effacés, phénomène que l'on peut attribuer à leur volonté de proposer un monde imaginaire séduisant, mais aussi à une évolution sociale plus large. Le grand nombre de représentations fictionnelles montrant des cliques d'enfants débarrassés de toute présence adulte et mettant l'accent sur les relations entre pairs évoque une caractéristique que les sociologues associent à l'adolescence et qu'Olivier Galland nomme "autonomie sans indépendance » (62). Dans ces œuvres, toutefois, le fait de se détacher, au moins par moments, de la sphère familiale pour se recentrer sur des fréquentations entre pairs n'est pas une caractéristique propre à l'univers adolescent. L'exclusion des parents fictionnels fait aussi partie de l'univers enfantin tel qu'il est conçu dans l'imaginaire contemporain, paradoxe résumé ainsi par Lynne Lundquist: «dans les films sur les valeurs familiales, il n'y a pas de familles » (161). La différence entre teen movies et films familiaux ne dépend pas de l'absence des parents à l'intérieur des fictions, mais de leur absence devant les écrans, or celle-ci est conditionnée par de nombreux éléments textuels soigneusement calibrés par les industries culturelles pour ne s'adresser qu'aux adolescents au détriment des adultes, exclus du visionnage. En d'autres termes, les rapprochements entre enfants et adolescents ne signifient pas que ces deux publics se confondent, mais que la frontière s'est déplacée vers d'autres critères.

21 Ces analyses indiquent, sur le plan sociologique, la contamination croissante de la sphère enfantine par l'adolescence et l'expansion de la catégorie des pré-adolescents. Or la rapidité avec laquelle des auteurs comme Galland traitent la pré-adolescence manifeste le flottement théorique qui entoure cette notion doublement liminaire. Quels sont donc ces éléments qui définissent la sphère enfantine ? On peut ici les résumer par deux traits : effacement de la sexualité ou, plus généralement, mise entre parenthèses de la dimension romantique; et présence d'un modèle initiatique souvent figuré par une quête. Ces deux caractéristiques sont d'ailleurs solidaires, la dimension sentimentale étant fréquemment présentée comme une diversion par rapport au processus de formation (interne) symbolisé par la quête.

La différence la plus évidente entre enfance et adolescence est la désexualisation de la culture familiale et enfantine, préoccupation principale des téléspectateurs parents s'exprimant sur les forums de discussion, comme l'indiquent les débats récents autour de la réception de Stranger Things. Cette série croisant science-fiction et horreur constitue un objet intéressant, dans notre perspective, car elle comporte à la fois des personnages d'enfants et d'adolescents. C'est sans doute l'une des raisons pour lesquelles elle a été rapprochée du film d'aventures Les Goonies (The Goonies, Warner Bros., Richard Donner, 1985), écrit par Chris Columbus, issu d'une idée originale de Steven Spielberg et dont les protagonistes mêlent eux aussi enfants et adolescents. Or, si les commentaires des téléspectateurs semblent indiquer que le film Les Goonies est 
adapté à un visionnage familial, il n'en va pas de même de Stranger Things. Une téléspectatrice américaine qui dit avoir regardé la série "avec sa fille de onze ans (presque douze)", la juge "parfaite pour les tweens et les plus âgés ", mais précise quelques lignes plus bas qu'elle a «sauté toutes les scènes de sexualité ado et de consommation d'alcool ». Plus loin, une internaute, qui ne recommande la série qu'aux " quatorze ans et plus ", écrit : "Ce n'est pas tant la dimension effrayante qui a rendu [la série] problématique pour ma pré-ado, mais le fait qu'une protagoniste et son copain [fassent] l'amour deux fois pendant la saison. » Un troisième, "parent de deux enfants, de dix et treize ans", raconte avoir arrêté de regarder en raison de l' « importante intrigue parallèle qui raconte la relation adolescente naissante entre un garçon et une fille ». Ces remarques convergentes attestent bien sûr les inquiétudes soulevées, notamment aux États-Unis, par la représentation de la sexualité et de ses effets. Mais elles manifestent aussi une différenciation implicite entre enfants, teen et tweens qui ne recoupe pas entièrement les bornes que la psychologie assigne à l'adolescence. Par-delà le puritanisme supposé du public, on peut estimer qu'est ici en jeu la délimitation d'un univers adolescent spécifique, marqué par la mise en avant de la sphère amoureuse. La puberté et les émois amoureux continuent donc de fonctionner comme marqueurs de l'entrée en adolescence. («Parent reviews for Stranger Things »).

Revenons à présent sur la comparaison, fréquemment mobilisée par les spectateurs, entre Stranger Things et Les Goonies. Les deux œuvres partagent bien sûr des caractéristiques génériques: la dimension fantastique, la présence d'un univers parallèle menaçant et le fait que le groupe de personnages principaux soit composé à la fois d'enfants ou pré-adolescents et d'adolescents plus âgés, déjà presque de jeunes adultes. Toutefois, l'analogie s'arrête là. Dans Stranger Things, les intrigues relevant de l'univers teen, les romances notamment, reçoivent un traitement relativement approfondi, constituant un fil parallèle important. À l'inverse, le fil teen est rapidement abandonné dans Les Goonies. Contrairement à Stranger Things, Les Goonies est un bon exemple d'œuvre intégrant des protagonistes adolescents dans un récit qui reste familial. Le récit des Goonies suit donc quatre protagonistes, petite clique d'enfants et de pré-adolescents, à laquelle vient s'ajouter le grand frère de l'un d'entre eux, Brand, âgé d'environ seize ans. Ce personnage pourrait rattacher le film à l'univers du teen movie, tout comme ses camarades de classe, personnages secondaires tout droit sortis d'une œuvre de John Hughes. Mais à l'inverse de ce qui se produit dans Stranger Things, Les Goonies se distancie très vite de cet ancrage adolescent pour se concentrer sur le récit d'aventures. On pourrait interpréter cela comme la simple conséquence de la différence de format, la forme sérielle permettant, comme on le sait, davantage de polyphonie narrative que le long-métrage. Mais notre hypothèse est qu'il s'agit aussi et surtout d'une question de focalisation et de délimitation générique. Un passage du film manifeste nettement cette mise à distance des motifs et des personnages adolescents. Dans le premier tiers du récit, alors qu'il avance, grotesque, sur un vélo d'enfant beaucoup trop petit pour lui, Brand est interpellé, puis dépassé par un groupe d'adolescents mieux intégrés dans leur groupe de pairs et assez âgés pour circuler à bord d'une superbe voiture décapotable. Parmi eux, un jeune homme sûr de lui conduit la voiture aux côtés d'une jeune fille séduisante. Un plan en insert montre brièvement un rétroviseur dans lequel se découpent les cuisses de l'héroïne, montrées en plan subjectif à travers le regard concupiscent du conducteur du véhicule, qui profite de son passage près du héros pour l'humilier. Ici, la sexualité est non seulement restreinte à 
un seul plan rapide au lieu d'être déployée au sein d'une séquence autonome, mais condamnée par ce plan en insert qui connote le voyeurisme de ce regard objectifiant. Tel un enfant qui détourne le regard, le film semble ainsi exprimer un rejet des premiers feux de la sexualité. Le signal est aussi adressé aux parents, puisque le film indique nettement qu'il va respecter un contrat : n'évoquer la sexualité que par les plus brefs et pudiques détours.

Cette figure absurde, un garçon trop grand pour ce petit vélo, peut être vue comme l'incarnation d'un artifice permettant au récit de rester familial: un portrait de l'adolescent en enfant éloigné des tourments de l'adolescence. La maladresse du personnage est rassurante, puisqu'elle garantit que sa sexualité et son rapport aux filles demeurent gauches, tâtonnants, et ne représentent rien de menaçant ni de conquérant. Plus qu'une figure d'entre-deux, Brand est une synthèse évoquant l'archétype de l'adulte au cœur d'enfant, que l'on retrouve fréquemment dans les films familiaux. Ce personnage type, analysé notamment par Douglas Brode (340), signifie une réconciliation intergénérationnelle.

Un processus analogue à celui des Goonies peut être identifié dans Ready Player One, roman d'Ernest Cline paru en 2011 et adapté en 2018 par Steven Spielberg. Si dans Les Goonies, le processus d'exclusion se fait au détour d'une scène, il s'accomplit dans Ready Player One à l'intérieur de la fiction, par le biais du parcours du personnage. Le roman de Cline parle d'un adolescent, Wade, âgé de quatorze ans, qui voue sa vie à la progression dans un gigantesque jeu vidéo à taille mondiale, l'OASIS, au cours duquel les joueurs de la planète entière cherchent désespérément des indices dissimulés dans le monde virtuel par un inventeur génial. Wade est l'archétype du geek, figure adolescente, certes, mais relativement désexualisée puisque, comme l'écrit David Peyron, il « est souvent mal à l'aise avec lui-même, avec son corps qu'il voudrait posthumain voire cyborg, avec le sexe et avec les filles qui sont vues comme des êtres étranges et hostiles ». Une citation du roman est très révélatrice de la mise à distance des enjeux adolescents. Au cours d'une des épreuves qui lui sont imposées, le héros se retrouve immergé à l'intérieur d'un film dont on a reconstitué le décor. Il raconte alors : « Je remarquai mon reflet sur l'écran du jeu. Ce n'est pas le visage de mon avatar que je vis apparaître. C'était celui de Matthew Broderick. Un jeune Matthew Broderick, avant Ferris Bueller et avant Ladyhawke " (Cline 108). L'intertexte et la référence à Matthew Broderick ne sont pas anodins. Broderick fut l'une des figures les plus marquantes du bratpack, le groupe d'acteurs américains des années 1980 qui ont incarné la quintessence de la culture adolescente, notamment, dans le cas de Broderick, avec le film La Folle journée de Ferris Bueller (Ferris Bueller's Day Off, Paramount, John Hughes, 1986). Or, comme le précise le héros, l'image de Matthew Broderick convoquée ici est précisément antérieure à ces films pour adolescents et se situe tout juste au seuil de l'adolescence. Il s'agit donc bien de donner au héros, pourtant âgé de quatorze ans, une identité encore proche de l'enfance.

C'est, sans aucun doute, cette caractéristique qui a attiré l'attention de Steven Spielberg, dont l'adaptation cinématographique a encore amplifié l'orientation vers un public familial. Par soustraction, d'abord, puisque certains éléments ont été supprimés du film, notamment l'épisode au cours duquel le héros s'achète une poupée gonflable pour tromper sa solitude, mais aussi tous les passages du livre situés dans le lieu par excellence de la culture adolescente, le lycée. En outre, même si l'on retrouve des situations adolescentes topiques, aussi bien dans le film que dans le livre, celles-ci sont, 
dès le livre de Cline, très largement éclipsées par le schéma de la quête. Le roman intègre à sa narration le processus consistant à reléguer hors champ ce qui relève de la relation amoureuse naissante entre les deux héros ou des relations entre pairs: Art3mis, la jeune fille dont Wade est amoureux, abandonne le héros pour le laisser se consacrer à sa quête, après quoi Wade coupe brutalement les ponts avec tous ses amis, entamant une existence d'ermite. Une fois supprimée la poupée gonflable, le geek est parfaitement intégrable à un récit pour enfants focalisé autour d'une initiation. Il n'est d'ailleurs pas anodin que le roman ait été comparé à un autre célèbre récit pour enfants reposant sur une quête, Charlie et la Chocolaterie de Roald Dahl (1964) par un critique de USA Today ( Ready Player One »).

Ce constat nous amène à une autre caractéristique qui définit le récit enfantin ou familial : la présence d'un schéma initiatique et d'un processus de maturation. Aussi paradoxal que cela puisse sembler, le schéma de formation montrant le passage de l'enfance à l'âge adulte est plus présent dans les œuvres pour enfants que pour adolescents. L'une des raisons de cette divergence tient peut-être au fait que les récits pour enfants reposent davantage sur des schémas empruntés aux contes, marqués par une logique édificatrice visant à mener les lecteurs vers la maturité, là où les récits pour adolescents obéissent plutôt à une logique hédoniste du moment présent, voire de la parenthèse. Les personnages de teen movies se satisfont de l'ici et maintenant de l'adolescence et ne cherchent en aucune manière à rejoindre l'univers des adultes. La présence d'un schéma initiatique menant le héros de l'enfance à l'âge adulte est un trait qui unit œuvres de fantasy pour enfants et pour adultes où, comme l'écrit Mike Ashley, " les protagonistes sont souvent enfants au début du livre, mais parviennent en général à l'âge adulte au cours de leurs aventures ». Les quêtes dans lesquelles s'engagent les héros en viennent alors à constituer une "stratégie permettant de mettre en scène [...] la croissance qui mène littéralement l'enfant ou l'adolescent vers l'âge adulte " (Ashley 184, cité par Slusser et Westfahl XIII). Ces récits structurés autour de quêtes initiatiques se caractérisent par un double mouvement, d'ouverture progressive - ou brutale - aux enjeux de l'univers adulte et de progression vers la maturité. Les œuvres qui les mobilisent, des classiques de la fantasy comme Le Seigneur des anneaux aux ouvrages pour enfants comme Le Monde de Narnia, sont susceptibles de séduire à la fois les adultes et les enfants. À l'inverse, la culture adolescente populaire s'est construite sur un double refus, celui de la formation et de la double adresse. La disparition relative d'un schéma initiatique est d'ailleurs l'une des critiques que Gary Kern formule à l'encontre de la culture adolescente populaire qui a émergé dans les années 1950. Il évoque avec nostalgie l'époque "innocente ", antérieure à l'émergence de la culture jeune après 1945, où les adolescents fictionnels «n'étaient pas [représentés comme] des êtres humains pleinement formés : ils ne remettaient pas en question l'autorité des adultes [...] mais cheminaient [...] vers la maturité » (Kern 50).

L'absence du schéma de formation va de pair avec le rejet d'un visionnage intergénérationnel. Il est significatif que dans Transcending Boundaries: Writing for a Dual Audience of Children and Adults, ouvrage pourtant consacré à la double adresse en littérature de jeunesse, le chapitre de John Stephens soit axé sur une œuvre, la série télévisée australienne Lockie Leonard (Nine Network, 2007-2010), qui constitue selon lui une exception.

Les livres de Tim Winton destinés à des «enfants plus grands » sont écrits dans un

langage qui imite l'idiome des pré-adolescents, mettent en scène des personnages

qui n'ont pas plus de quatorze ans, et visent un public ayant entre dix et quatorze 
ans. Ils séduisent des « jeunes adultes » tout en bas de cette tranche d'âge, mais ne

présentent pas le moindre attrait pour des lecteurs adultes. (Stephens 183)

Pour décrire cette œuvre qui ne cible qu'une classe d'âge à la fois et exclut le public adulte, l'auteur glisse progressivement de l'expression "enfants plus âgés » à " préadolescents». Ce changement de désignation peut s'expliquer par le fait que cette œuvre exclusive n'appartient pas au champ de la culture de l'enfance, mais s'inscrit déjà dans la culture adolescente. Cette hypothèse est confirmée par l'examen de l'œuvre en question. La série littéraire Lockie Leonard comporte des passages ouvertement érotiques et la version télévisée obéit nettement aux schémas des récits teen: recentrement sur les relations entre pairs, intrigues de lycée et premières amours.

La troisième étape de notre réflexion va justement nous amener à étudier plus en détail le fonctionnement de cette culture teen qui, sous l'influence des industries culturelles, s'est focalisée sur les adolescents, à l'exclusion de leurs parents, mais aussi de leurs jeunes frères et sœurs.

\section{Le monde de l'adolescence : stratégies de différenciation}

Si les chercheurs spécialisés dans la culture de jeunesse ont tendance à éluder la question de la différence entre adolescence et enfance, ceux qui s'intéressent à l'adolescence accentuent au contraire la différence radicale séparant les adolescents de leurs petits frères et sœurs. L'enjeu n'est donc plus l'exclusion des adultes du contenu fictionnel, mais l'exclusion des adultes lecteurs ou spectateurs par le biais de stratégies de ciblage singulières qui ne se contentent pas de proposer des protagonistes adolescents, mais s'efforcent également de refléter leurs préoccupations et de parler leur langage.

31 Les industries culturelles - notamment les producteurs de contenu audiovisuel - ont assez vite envisagé de manière précise la distinction entre enfance et adolescence en termes de public-cible, quitte peut-être à l'accentuer, poussées par une logique économique. L'intérêt économique d'une distinction précise entre enfance et adolescence dans le domaine de la culture de masse est double. D'une part, cette distinction reflète sans doute le désir des adolescents de ne plus être considérés comme des enfants, elle permet donc de séduire et de flatter un public-cible qui revendique cette séparation nette. D'autre part, cette différenciation permet de maximiser les ventes en segmentant le public en classes d'âge toujours plus restreintes. L'émergence de ce ciblage spécifique d'un public adolescent, d'abord aux États-Unis, a été analysée par les sociologues et les spécialistes des industries culturelles, et datée, approximativement, des années 1940. En amont même de cette période, les travaux de Susan Ohmer consacrés à l'utilisation des sondages à Hollywood par le studio RKO montrent que dès la fin des années 1930, une culture spécifiquement juvénile a émergé, tandis que "publicitaires et responsables de marketing commençaient à admettre l'existence d'un nouveau marché en plein essor » (Ohmer 132). Selon Ohmer, les studios prirent rapidement conscience de la nécessité de distinguer les adolescents du public enfantin.

L'institut éplucha les catalogues des bibliothèques pour y chercher des ouvrages destinés aux adolescents qui seraient susceptibles d'être adaptés à l'écran et 
recommanda à la RKO la série de romans organisés autour du personnage de l'infirmière Sue Barton. [On] suggéra même à la RKO de modifier des histoires destinées aux enfants pour y inclure des adolescents à la place [des héros d'origine]. (Ohmer 132)

Un processus analogue s'est opéré à la télévision américaine dans les années 1950, avec l'élaboration, sur la chaîne généraliste $A B C$, de programmes destinés aux jeunes (Blue 17). Les analyses de Mary Celeste Kearney indiquent que les séries télévisées ont, au cours des années 1950, accordé une place croissante aux personnages d'adolescents, ce qui a conduit à terme à l'apparition d'œuvres destinées spécifiquement aux adolescents. Cette production télévisuelle ciblée a connu, après un déclin dans les années 1970, un renouveau entre la fin des années 1990 et le début des années 2000. Cela tient à des raisons démographiques: l'arrivée d'une nouvelle génération d'adolescents qu'on a appelée "écho-boom » ou "génération $Y$ ». La création de la chaîne The WB, concurrente de MTV, est la meilleure illustration de ce renouveau (Wee 46). Selon Valerie Wee, « dans les années 1990, [...] le terme "teen" s'est peu à peu détaché de l'âge biologique et a été de plus en plus associé à un mode de vie, des goûts et des intérêts culturels partagés » (47). De la même manière, Adrian Martin souligne que «le teen du teen movie est un terme très élastique, et soumis à variation; il ne renvoie pas à un âge biologique, mais à un type, un genre de comportement, une manière d'être... Le teen d'un teen movie désigne plutôt quelque chose comme la jeunesse » (67).

32 C'est à la manière dont les produits culturels ont tenté de capter, reproduire et réinventer ce mode de vie adolescent que l'on va s'intéresser à présent, en tentant de définir les différents traits qui composent cet imaginaire de l'adolescence dans la culture populaire. Avant d'en détailler les composantes, notons que la vision de l'adolescence qui circule dans l'imaginaire de la culture de masse a notamment été modelée, plus ou moins consciemment, par l'influence de théories développées en psychanalyse depuis les débuts $\mathrm{du} \mathrm{xx}^{\mathrm{e}}$ siècle. Parmi celles-ci, on peut mentionner en premier lieu le manuel du psychologue Stanley Hall paru en 1916, qui associe l'adolescence au tourment et au trouble (storm and stress). Dans la culture populaire et auprès des parents, le célèbre manuel d'éducation du docteur Spock, paru en 1946, contribua à infléchir le style éducatif nord-américain des baby-boomers dans le sens d'un déclin de l'autoritarisme. Enfin, l'accent mis, notamment par le psychiatre Erik Erikson, sur l'identité psychosociale de l'adolescent allait se retrouver dans les trames de récits largement axés sur l'insertion dans un groupe et sur les enjeux de popularité (Erikson 124 ; Cohen-Scali et Guichard 321-345).

33 Le premier point important concerne l'âge des protagonistes : l'adolescent archétypal, tel qu'on le rencontre dans les teen movies et les teen series, se situe en général dans le haut de la fourchette d'âge et a entre seize et dix-sept ans. Le roman avec lequel on fait parfois démarrer l'émergence d'une littérature pour adolescents, Seventeenth Summer de Maureen Daly (1942), concerne d'ailleurs, comme son titre l'indique, une hérö̈ne de dix-sept ans. La préférence pour des adolescents déjà grands s'explique peut-être par la volonté de bien marquer, là encore, la différence avec l'enfance, afin d'éviter la représentation de corps trop proches de l'enfance, dès lors que sont abordées des thématiques liées à l'émergence de la sexualité. La différence avec l'enfance se marque d'ailleurs souvent par un personnage de petit frère ou d'une petite sœur qui, par sa simple présence, délimite négativement les territoires respectifs de l'enfance et de l'adolescence. 

deux grands traits : la mise entre parenthèses de l'univers et des valeurs adultes, d'une part, et l'élaboration d'une tonalité spécifique, dégagée du didactisme et du paternalisme, de l'autre. Corollaire de ces deux points, on peut ajouter, à l'inverse de ce qu'on a étudié plus haut pour les œuvres familiales, une dynamique narrative caractérisée plutôt par la suspension dans un éternel présent que par l'avancée vers la maturité. En ce qui concerne, premièrement, l'organisation des récits autour du point de vue des adolescents, l'enjeu est à la fois narratif et idéologique. Dans l'article précédemment cité, Gary Kern oppose à la culture contemporaine, marquée selon lui par le triomphe des valeurs jeunes, une époque, évoquée avec nostalgie, où «le monde adolescent restait toujours subordonné au monde des adultes » et où, «même lorsque le film se concentrait entièrement sur les adolescents, les héros, par leurs paroles et par leurs actes, laissaient deviner la présence d'un monde extérieur qu'ils n'avaient pas encore intégré " (Kern 41). Si l'on soustrait de ces considérations leur dimension polémique, on peut retenir un trait fondamental des films de la culture adolescente : la volonté de décentrer les enjeux adultes. Les spécialistes de littérature pour adolescents aux États-Unis s'accordent à reconnaitre comme canoniques les ouvrages Seventeenth Summer de Maureen Daly (1942) et The Outsiders de Susan Hinton (1967). Le premier est un bon exemple d'approche nombriliste, resserrée sur son héroïne, le second est le point de départ du courant des romans pour adolescents traitant de questions sociales (social problem novels), par contraste avec la littérature d'évasion (Cart 25). De ces deux voies, on peut considérer que la culture populaire, tout particulièrement le courant du teen movie, a privilégié la première, celle de Maureen Daly, plus attentive aux émois intérieurs de son personnage qu'à la société environnante. Ce genre de romance légère a souvent été reçu avec une certaine condescendance par les critiques, ironisant, à l'instar de Michael Cart, sur ces «livres situés dans un monde tout droit sorti du Saturday Evening Post ${ }^{3}$ - un monde de visages et de palissades blancs où le pire qui puisse arriver aux personnages serait de se retrouver au bal de fin d'année sans cavalier " (25). Même en dehors du genre majoritairement féminin de la romance, cette focalisation sur l'univers et la psychologie des adolescents constitue la norme dans la culture teen. On peut voir dans ce type de récits l'ancêtre d'œuvres dont le point commun - en dépit des formes diverses qu'elles peuvent prendre, de la bluette aux débordements grotesques ou sanglants des comédies au-dessous de la ceinture ou des films d'horreur - est de placer résolument la perspective adolescente au centre, traitant le reste du monde, les adultes en particulier, comme des figurants en retrait. En dépit du succès de The Outsiders et de son statut de roman culte, force est de constater que les productions qui ont marqué le couronnement de la culture teen populaire sont bien ces œuvres légères, autocentrées et souvent jugées futiles par les adultes : marivaudages de Rose bonbon (Pretty in Pink, Paramount, Howard Deutch, 1986), humour plus graveleux d'American Pie et manigances tortueuses de Clueless (Paramount, Amy Heckerling, 1995) ou Lolita malgré moi (Mean Girls, Paramount, Mark Waters, 2004).

À cela vient s'ajouter, comme on l'a dit, la recherche d'un ton adapté au public adolescent et caractérisé par le refus du didactisme explicite, non seulement dans les comédies, mais aussi dans des genres a priori plus sombres - l'horreur, par exemple. Cette tonalité légère se distingue radicalement à la fois du ton paternaliste de certains classiques de romans pour enfants et de la dramatisation pesamment moralisatrice que l'on trouvait dans certains teen flicks des années 1920. Cette élaboration progressive d'un ton particulier, entre insolence et futilité, permet de comprendre l'évolution du 
teen movie au cours des années 1940, puis 1950, ainsi que les politiques de programmation télévisuelles évoquées plus haut. Ainsi, Valerie Wee souligne que la chaîne MTV s'employait « activement et ouvertement à éloigner et à tenir à distance les téléspectateurs qui n'étaient pas des adolescents, en produisant des contenus exclusivement tournés vers les adolescents » (54).

Le ciblage d'un public jeune a donc entrainé, en parallèle avec l'émergence, puis l'affirmation de la culture jeune depuis l'après-guerre, la mise au point d'un ton spécifique et inédit, une certaine manière d'interpeller les jeunes, de parler leur langage et d'adopter, en apparence du moins, leur état d'esprit présumé. Ces représentations teen continuent d'être, dans leur grande majorité, conçues pour des adolescents par des adultes. Mais ces derniers ont peu à peu appris les arcanes du parler jeune et adopté une voix empruntée notamment à la presse jeunesse de l'époque, basculant, dans les années 1950, d'un ton docte et paternaliste à une perspective plus soucieuse de séduire que d'éduquer. Désormais on « s'adress[ai]t à l'adolescent comme à un égal » et l'enjeu n'était plus « de le faire accéder à l'âge adulte, mais de rendre son adolescence plus agréable » (Shary 46-47).

Ce ton singulier nous semble aller de pair avec le refus, mentionné plus haut, des schémas initiatiques. Certains spécialistes de la littérature de jeunesse ont d'ailleurs déploré le passage de la célébration de « la continuité, la persévérance et la maturation progressive » à une " nouvelle philosophie [...] célébrant l'incohérence, la passivité et l'immobilité » (Westfahl 44), et le basculement d'un schéma privilégiant la «formation » à un modèle de " développement interrompu » (Slusser 75) qui a débuté avec les " premiers films pour adolescents » sortis sur les écrans après 1945 et culminé dans les années 1980. Selon Georges Slusser,

[o]n trouve des phénomènes analogues dans les films populaires américains. Dans les films des années 1980 qu'on a surnommés "brat pack films", les figures d'autorité parentale sont de plus en plus tournées en ridicule et marginalisées pour leur inefficacité. En même temps, lorsque les adolescents de ces films échangent entre eux pour résoudre les problèmes posés par l'entrée dans l'âge adulte, ils découvrent vite que la solution la plus efficace consiste à ne pas grandir. (Slusser 75-76)

La phrase finale de Seventeenth Summer nous semble très représentative de ce refus de grandir et de la volonté de prolonger autant que possible la parenthèse de l'adolescence : «Et j'eus soudain la révélation que cela pourrait continuer à jamais, passer en un instant et que jamais pourtant il n'y aurait rien de plus merveilleux que cet été de mes dix-sept ans! » (Daly 185)

Il reste à interroger l'extension de caractéristiques adolescentes à des classes d'âge que l'on rattachait auparavant à l'enfance ou, pour le formuler autrement, la contamination partielle de la culture de l'enfance par les codes de la culture adolescente. C'est sur cette classe d'âge difficile à cerner et d'autant plus problématique qu'elle suscite une « panique sociale » évidente, la pré-adolescence, que l'on achèvera ce parcours.

La gêne avec laquelle est traité le personnage du pré-adolescent, situé entre l'enfance et l'adolescence, potentiellement sexualisé mais non sexualisable, a longtemps été manifestée par sa sous-représentation. On pourrait, bien sûr, citer quelques exceptions, tel le protagoniste du film d'animation Monster House, qui est parsemé d'allusions à cet état d'entre-deux et au processus pubertaire (Howarth 204). Mais pendant longtemps, cette figure a été assez peu présente sur les écrans de cinéma ou de télévision - les deux choix les plus simples consistant soit à l'éviter, en s'en tenant à des figures fictionnelles 
d'adolescents déjà grands, soit à la rattacher à l'univers de l'enfance, comme on l'a examiné dans les récits d'aventure mentionnés plus haut.

Mais, selon une logique analogue à celle que l'on a retracée pour les adolescents des années 1950, la logique de segmentation des marchés a conduit à l'élaboration de la catégorie marketing des tweens, ces pré-adolescents (et surtout pré-adolescentes, le phénomène étant nettement genré) qui lorgnent déjà vers les attitudes et les comportements des adolescents (Blue 18). La découverte des tweens a entraîné au début des années 2000 l'apparition de personnages d'adolescents et d'adolescentes plus jeunes. On trouve un bon exemple de ce traitement hésitant des figures préadolescentes dans la série Lizzie McGuire lancée en 2001 sur Disney Channel, qui raconte les aventures d'une héroïne de douze ans. Le statut incertain du personnage, oscillant entre enfance et adolescence, est manifesté par la présence des parents qui occupent une place plus importante que dans une série teen habituelle, notamment la mère de l'héroïne, qui apparaît régulièrement pour prodiguer des conseils avisés à sa fille. Mais ce statut hybride se manifeste surtout par l'apparition récurrente d'un avatar animé de l'héroïne, qui fait de fréquents apartés et ramène le personnage du côté de l'enfance bien que des seins naissants soient dessinés sur le T-shirt de l'avatar, discret rappel de son état pubertaire. On peut supposer que ce personnage animé manifeste la difficulté pour une chaine notoirement destinée à un public familial comme Disney Channel de traiter ce corps en transformation. Mais tout le reste de la série la désigne nettement comme un produit pour adolescents et adolescentes, et non comme un programme pour enfants. On y retrouve tous les thèmes, situations et personnages types du récit adolescent : le premier épisode s'ouvre sur le projet de Lizzie de devenir majorette, met au premier plan les relations entre pairs, la question de la réputation, les hiérarchies de réputation entre les élèves du collège et comporte des personnages types, notamment la chipie populaire et d'apparence plus mature que l'héroïne. Même les motifs narratifs - vengeances, rivalités, dissimulations - évoquent les classiques de la culture adolescente (Boutang et Sauvage 24). On a ainsi affaire à un produit limite, véritablement à la lisière entre enfance et âge adulte, marqué génériquement par le modèle adolescent légèrement édulcoré et transposé à des figures plus jeunes. Comme dans d'autres œuvres étudiées plus haut, le personnage du petit frère de l'héroïne signifie bien, par différenciation, que celle-ci a quitté la sphère de l'enfance. Les œuvres accentuant explicitement le statut de tween sont plus rares et correspondent à une tendance très récente. On peut mentionner l'étrange Good Boys (Universal, Gene Stupnitsky, 2019), qui joue constamment sur le statut d'entre-deux de ses personnages (trois garçons de douze ans) : ceux-ci se désignent eux-mêmes à plusieurs reprises comme tweens dans la fiction. Avec ce film, toutefois, on atteint les limites des stratégies de double adresse : Good Boys est en effet émaillé de plaisanteries grivoises qui le rendent inaccessible à un public de cet âge (il a été classé PG-13 aux États-Unis), mais l'âge de ses protagonistes le rend assez peu attractif pour un public plus âgé, un calcul hasardeux, comme l'a montré son échec commercial.

\section{Conclusion : de 7 à 77 ans... mais pas 13 ?}

41 Cette étude s'est ouverte sur la difficulté de distinguer entre deux catégories mitoyennes, enfants et adolescents, et sur le fait que cette différence est souvent l'impensé de la réflexion consacrée à la littérature et à la culture jeunesse. Nous avons 
ici retracé le mécanisme qui a conduit à la confusion entre ces deux âges et les raisons qui l'expliquent, notamment le désir de contrôler une jeunesse jugée dangereuse et peu maitrisable. Il ne s'agissait pas de proposer des critères définitifs mais de révéler des distinctions établies de manière implicite par les œuvres, les producteurs de contenus culturels et les spectateurs. Cependant nous avons identifié plusieurs critères permettant de délimiter les sphères respectivement attribuées à la culture adolescente et à la culture d'enfance. Cette dernière peut, on l'a vu, être pensée comme l'équivalent d'une culture familiale réunissant enfants et parents autour de contenus intergénérationnels. Si la question de la sexualité reste évidemment primordiale, nous avons montré que la présence - ou, dans le cas de la culture adolescente populaire, l'absence - de modèles initiatiques classiques est également un critère fondamental. Des recherches ultérieures pourront notamment préciser en quoi les contenus diffèrent selon l'identité de genre des publics visés et selon les médias employés. L'aventure, par exemple, reste perçue comme masculine et la romance comme féminine. Par ailleurs, si le sous-genre de la dystopie adolescente, très différent des teen movies habituels, s'est considérablement développé au cinéma au cours des dernières décennies, on peut attribuer ce succès croissant au fait que ces œuvres cinématographiques sont des adaptations de romans - de la tétralogie Hunger Games (Lionsgate, Gary Ross, 2012 ; Francis Lawrence, 2013-2015) à la trilogie Divergente (Summit Entertainment, Neil Burger, 2014 ; Robert, Schwentke, 2015-2016), pour citer les deux séries dystopiques teen les plus célèbres.

Mais la question centrale reste celle du traitement ou de la création de ces figures d'entre-deux: les pré-adolescents. Comment interpréter l'émergence de la culture tween, dans le cadre de notre interrogation sur les limites entre culture adolescente et culture enfantine ou familiale? Sans doute justement non pas comme la marque d'une confusion croissante entre enfance et adolescence, mais comme celle de la contamination croissante de l'enfance par l'adolescence. Plus que de véritables entredeux, les tweens sont plutôt des adolescents précoces. Le sort réservé à ces figures est la manifestation la plus nette des deux processus opposés que met en évidence cet article : la difficulté d'envisager la continuité entre enfance et adolescence, d'un côté, et la logique inverse d'hyper-segmentation des publics, de l'autre. Et la gêne avec laquelle les industries culturelles manient les figures de pré-adolescents et de pré-adolescentes manifeste peut-être l'impasse de cette logique de l'extension de la culture adolescente. L'adolescent n'est pas, décidément, un enfant comme les autres et sa présence marque la fin de ce « film pour tous » dont avait rêvé le Hollywood classique.

BIBLIOGRAPHIE 


\section{Ouvrages et articles}

ASHLEY, Mike. «Children in Science Fiction ». The Encyclopedia of Science-Fiction. Dir. John Clute et Peter Nicholls. Londres : St. Martin's Press, 1997, p. 184.

BLUE, Genevieve Morgan. Girlhood on Disney Channel: Branding, Celebrity, and Femininity. New York : Routledge, 2017.

BRODE, Douglas. « Visionary Children and Child-like Heroes: Steven Spielberg's "Primal Sympathies" ». A Necessary Fantasy?: The Heroic Figure in Children's Popular Culture. Dir. Dudley Jones et Tony Watkins. New York: Garland Publishing, 2000, p. 330-341.

CAMPBELL, Beatrix, et Jennifer DAWSON. «Censorhip: Inside Stories ». Sight and Sound, vol. 4, n 9, 1994, p. 30-31.

CAREY, Tanith. «The "Sick-lit" Books Aimed at Children: It's a Disturbing Phenomenon. Tales of Teenage Cancer, Self-harm and Suicide... ». The Daily Mail, 3 janvier 2013.

dailymail.co.uk/femail/article-2256356/The-sick-lit-books-aimed-children-Its-disturbingphenomenon-Tales-teenage-cancer-self-harm-suicide-html.

Page consultée le 9 août 2019.

CART, Michael. Young Adult Literature: From Romance to Realism. 2010. Chicago : American Library Association, 2016.

CLINE, Ernest. Ready Player One. Londres : Century, 2011.

COHEN-SCALI, Valérie, et Jean GUICHARD. «L'identité : perspectives développementales ».

$L^{\prime}$ 'orientation scolaire et professionnelle, vol. 37, $\mathrm{n}^{\circ} 3,2008$.

journals.openedition.org/osp/1716.

Page consultée le 15 septembre 2018.

CORR, Charles. « Bereavement, Grief, and Mourning in Death-Related Literature for Children ». OMEGA - Journal of Death and Dying, vol. 48, n 4, 2004, p. 337-363.

DAHL, Roald. Charlie and the Chocolate Factory. New York : Alfred E. Knopf, 1964.

DALY, Maureen. Seventeenth Summer. 1942. New York : Simon \& Schuster, 1970.

DERRY, Charles. Dark Dreams 2.0: A Psychological History of the Modern Horror Film from the 1950s to the $21^{\text {st }}$ Century. Jefferson : McFarland, 2009.

DOHERTY, Thomas. Teenagers and Teenpics: Juvenilization of American Movies. Philadelphie : Temple University Press, 2002.

DRISCOLL, Catherine. « Girl-doll: Barbie as Puberty Manual ». Girl Culture: An Encyclopedia. Dir. Claudia Mitchell et Jacqueline Reid-Walsh. Londres : Greenwood press, 2007, p. 224-242.

ERIKSON, Erik. Insight and Responsibility. New York : Norton, 1964.

GALLAND, Olivier. Les Jeunes. 1984. Paris : La Découverte, 2009.

HALL, G. Stanley. Adolescence: Its Psychology and Its Relations to Physiology, Anthropology, Sociology, Sex, Crime, Religion and Education. 1904. Sydney : Wentworth Press, 2016.

HALL, Stuart, et Tony JEFFERSON. Resistance through Rituals: Youth Subcultures in Post-war Britain. Londres : Routledge, 1993.

HINTON, Susan. The Outsiders. New York : Viking Press, 1967. 
JAMESON, Fredric. The Cultural Turn: Selected Writings on the Postmodern, 1983-1998. New York: Verso, 1998.

HOWARTH, Michael. «Surreal Estate: Building Self-Identity in Monster House ». Kidding Around: The Child in Film and Media. Dir. Alexander N. Howe et Wynn Yarbrough. New York : Bloomsbury, 2014.

KEARNEY, Mary Celeste. « Recycling Judy and Corliss: Transmedia Exploitation and the First Teen-girl Production Trend ». Feminist Media Studies, vol. 4, n³ 3, 2004, p. 265-295.

KERN, Gary. « The Triumph of Teen-Prop ». Nursery Realms: Children in the Worlds of Science Fiction, Fantasy, and Horror. Dir. Edgar Sluller et Gary Westfahl. Athens : University of Georgia Press, 1999, p. 48-72.

LEWIS, C.S. The Chronicles of Narnia. 1950-1956. New York : Harper Collins, 1994.

LUNDQUIST, Lynne. « Coming of Age in Fantasyland ». Nursery Realms: Children in the Worlds of Science Fiction, Fantasy, and Horror. Dir. Edgar Sluller et Gary Westfahl. Athens : University of Georgia Press, 1999, p. 161-171.

MARTIN, Adrian. Phantasms. Ringwood : McPhee Gribble, 1994.

METTON Céline. « L'autonomie relationnelle. SMS, “chat” et messagerie instantanée ». Ethnologie française, vol. 40, n 1, 2010, p. 101-107.

MITCHELL, Claudia, et Jacqueline REID-WALSH. Seven Going on Seventeen: Tween Studies in the Culture of Girlhood. New York : Peter Lang, 2005.

MACDONALD, Fiona. Childhood and Tween Girl Culture: Family, Media and Locality. Londres : Palgrave Macmillan, 2017.

NIKOLAJEVA, Maria. Children's Literature Comes of Age: Toward a New Aesthetic. 1996. Londres : Routledge, 2016

OHMER, Susan. George Gallup in Hollywood. New York : Columbia University Press, 2006.

OSWELL, David. «A Question of Belonging: Television, Youth and the Domestic ». Cool Places: Geographies of Youth Cultures. Dir. Tracey Skelton et Gill Valentine, Londres : Routledge, 2005, p. 35-49.

«Parents reviews for Stranger Things ». Common Sense Media. www.commonsensemedia.org/tv-reviews/stranger-things. Page consultée le 24 septembre 2018.

PEARSON, Geoffrey. Hooligan: A History of Respectable Fears. Basingstoke : Macmillan, 1983.

PEYRON, David. « Une histoire de la figure du geek dans la culture populaire ». Komodo 21, $\mathrm{n}^{\circ} 5$, 2016.

komodo21.fr/histoire-de-figure-geek-culture-populaire.

Page consultée le 9 décembre 2019.

RABKIN, Eric S. «Infant Joys: The Pleasures of Disempowerment in Fantasy and Science Fiction ». Nursery Realms: Children in the Worlds of Science Fiction, Fantasy, and Horror. Dir. George Edgar Slusser et Gary Westfahl. Athens : University of Georgia Press, 1999.

SHARY, Timothy. Generation Multiplex: The Image of Youth in American Contemporary Cinema. Austin : University of Texas Press, 2002.

SHAVIT, Zohar. Poetics of Children's Literature. Athens : University of Georgia Press, 1986. 
SLUSSER, George Edgar. «The Forever Child: Ender's Game and the Mythic Universe of Science Fiction ». Nursery Realms: Children in the Worlds of Science Fiction, Fantasy, and Horror. Dir. George Edgar Slusser et Gary Westfahl. Athens : University of Georgia Press, 1999, p. 73-90.

SLUSSER, George Edgar, et Gary WESTFAHL. « Introduction: Return to Innocence ». Nursery Realms: Children in the Worlds of Science Fiction, Fantasy, and Horror. Dir. George Edgar Slusser et Gary Westfahl. Athens : University of Georgia Press, 1999, p. 9-13.

STEPHENS, John. « Maintaining Distinctions: Realism, Voice and Subject Distinctions in Australian Young Adult fictions ». Transcending Boundaries: Writing for a Dual Audience of Children and Adults. Dir. Sandra L. Beckett. New York: Garland, 1999, p. 183-200.

STINE, R.L. Goosebumps. New York : Scholastic Publishing, 1992-1997.

« Ready Player One: Willy Wonka meets Matrix ». USA Today, 28 juin 2013.

WEE, Valerie. « Teen Television and the WB Television Network ». Teen Television: Essays on Programming and Fandom. Dir. Sharon Marie Ross et Louisa Ellen Stein. Jefferson : McFarland, 2009, p. 43-60.

WESTFAHL, Gary. Science-fiction, Children's Literature, and Popular Culture: Coming of Age in Fantasyland. Westport : Greenwood, 2000.

\section{Films et programmes télévisés}

American Pie. Réal. Paul et Chris Weitz. Scénario d'Adam Herz. Avec Jason Biggs (Jim Levenstein), Chris Klein (Oz Ostreicher), Thomas Ian Nicholas (Kevin Myers), Eddie Kaye Thomas (Paul Finch), Tara Reid (Vicky Lathum), Mena Suvari (Heather Gardner), Seann William Scott (Steve Stifler), Alyson Hannigan (Michelle Flaherty). Universal, 1999.

Close Encounters of the Third Kind. Réal. Steven Spielberg. Scénario de Steven Spielberg. Avec Richard Dreyfuss (Roy Neary), François Truffaut (Claude Lacombe), Teri Garr (Ronnie Neary), Cary Guffey (Barry Guiler), Melinda Dillon (Jillian Guiler). Columbia Pictures, 1977.

Clueless. Réal. Amy Heckerling. Scénario d'Amy Heckerling. Avec Alicia Silverstone (Cher Horowitz), Stacey Dash (Dionne Davenport), Brittany Murphy (Tai Frasier), Paul Rudd (Josh Lucas). Paramount, 1995.

Divergent. Réal. Neil Burger. Scénario de Evan Daugherty et Vanessa Taylor. Avec Shailene Woodley (Tris Prior), Theo James (Tobias Eaton), Ashley Judd (Natalie Prior), Kate Winslet (Jeanine Matthews), Lionsgate, 2014.

Divergent Series (The): Allegiant. Réal Robert Schwentke. Scénario de Bill Collage, Adam Cooper, and Noah Oppenheim. Avec Avec Shailene Woodley (Tris Prior), Theo James (Tobias Eaton), Ashley Judd (Natalie Prior), Naomi Watts (Evelyn). Lionsgate, 2016.

Divergent Series (The): Insurgent. Réal Robert Schwentke. Scénario de Brian Duffield, Akiva Goldsman, Mark Bomback. Avec Shailene Woodley (Tris Prior), Theo James (Tobias Eaton), Ashley Judd (Natalie Prior), Kate Winslet (Jeanine Matthews), Naomi Watts (Evelyn). Lionsgate, 2015.

Empire of the Sun. Réal. Steven Spielberg. Scénario de Tom Stoppard. Avec Christian Bale (James Graham), John Malkovich ( Basie), Miranda Richardson (Madame Victor), Warner Bros., 1987.

E.T. the Extra-Terrestrial. Réal. Steven Spielberg. Scénario de Melissa Mathison. Avec Dee Wallace (Mary), Peter Coyote (« Keys »), Henry Thomas (Elliott). Universal Pictures, 1982. 
Ferris Bueller's Day Off. Réal. John Hughes. Scénario de John Hughes. Avec Matthew Broderick (Ferris Bueller), Alan Ruck (Cameron Frye), Mia Sara (Sloane Peterson), Jennifer Grey (Jeanie Bueller), Jeffrey Jones (Edward R. Rooney). Paramount, 1986.

Good Boys. Réal. Gene Stupnitsky. Scénario de Gene Stupnitsky et Lee Eisenberg. Avec Jacob Tremblay (Max), Keith L. Williams (Lucas), Brady Noon (Thor). Universal, 2019.

Goonies (The). Réal. Richard Donner. Scénario de Chris Columbus, sur une histoire originale de Steven Spielberg. Avec Sean Astin (Michael « Mikey » Walsh), Josh Brolin (Brandon « Brand » Walsh), Jeff Cohen (Lawrence « Chunk » Cohen), Corey Feldman (Clark « Mouth » Devereaux), Kerri Green (Andrea « Andy » Carmichael), Martha Plimpton (Stephanie « Stef » Steinbrenner), Jonathan Ke Huy Quan (Richard « Data » Wang). Warner Bros., 1985.

Hunger Games (The). Réal. Gary Ross. Scénario de Suzanne Collins, Gary Ross et Billy Ray. Avec Jennifer Lawrence (Katniss Everdeen), Josh Hutcherson (Peeta Mellark), Liam Hemsworth (Gale Hawthorne), Woody Harrelson (Haymitch Abernathy), Elizabeth Banks (Effie Trinket), Lionsgate, 2012.

Hunger Games (The): Catching Fire. Réal. Francis Lawrence. Scénario de Simon Beaufoy et Michael deBruyn. Avec Avec Jennifer Lawrence (Katniss Everdeen), Josh Hutcherson (Peeta Mellark), Liam Hemsworth (Gale Hawthorne). Lionsgate, 2013.

Hunger Games (The): Mockingjay (Part 1). Réal. Francis Lawrence. Scénario de Danny Strong. Lionsgate, 2014.

Hunger Games (The): Mockingjay (Part 2). Réal Francis Lawrence. Scénario de Peter Craig et Danny Strong. Lionsgate, 2015.

Indiana Jones and the Temple of Doom. Réal. Steven Spielberg. Scénario de George Lucas. Avec Harrison Ford (Indiana Jones), Kate Capshaw (Willie Scott). Paramount, 1984.

Lizzie McGuire. Créé par Terri Minsky 2001. Avec Hilary Duff (Lizzie McGuire), Lalaine (Miranda Sanchez), Adam Lamberg (David Gordon), Jake Thomas (Matt McGuire). Disney Channel, 2001-2004

Lockie Leonard. Créé par Tim Winton. Avec Sean Keenan (Lockie Leonard), Rhys Muldoon (Sarge Leonard), Briony Williams (Joy Leonard). Nine Network, 2007-2010.

Mean Girls. Réal. Mark Waters. Scénario de Tina Fey. Avec Lindsay Lohan (Cady Heron), Rachel McAdams (Regina George), Lacey Chabert (Gretchen Wiener), Amanda Seyfried (Karen Smith), Lizzy Caplan (Janis Ian). Paramount, 2004.

Nightmare on Elm Street (A). Réal. Wes Craven. Scénario de Wes Craven. Avec Heather Langenkamp (Nancy Thompson), John Saxon (Lt. Donald Thompson), Robert Englund (Fred « Freddy » Krueger), Johnny Depp (Glen Lantz), Ronee Blakley (Marge Thompson). New Line Cinema, 1984.

Pretty in Pink. Réal. Howard Deutch. Scénario de John Hughes. Avec Molly Ringwald (Andie Walsh), Harry Dean Stanton (Jack Walsh), Jon Cryer (Philip Dale), Annie Potts (Iona), James Spader (Steff McKee), Andrew McCarthy (Blane McDonough), Kate Vernon (Benny Hanson), Andrew Dice Clay (Bouncer). Paramount, 1986.

Scream. Réal. Wes Craven. Scénario de Kevin Williamson. Avec Neve Campbell (Sidney Prescott), David Arquette (Dewey Riley), Courteney Cox (Gale Weathers), Skeet Ulrich (Billy Loomis), Matthew Lillard (Stu Macher), Rose McGowan (Tatum Riley), Jamie Kennedy (Randy Meeks), Drew Barrymore (Casey Becker). Woods Entertainment/Dimension Films, 1996. 
Stranger Things. Créé par Matt et Ross Duffer. Avec Winona Ryder (Joyce Byers), David Harbour (Jim Hopper), Finn Wolfhard (Mike Wheeler), Millie Bobby Brown (Eleven/Jane Hopper), Gaten Matarazzo (Dustin Henderson) Netflix, 2016-.

\section{NOTES}

1. En sociologie, la différence entre enfance et adolescence peut se résumer à la formule efficace de Céline Metton: une "autonomie relationnelle», détachée toutefois de l'indépendance financière qui caractérise l'âge adulte (Metton citée par Galland 63). Pour les psychologues, en schématisant bien sûr des courants théoriques qui peuvent diverger, la singularité de l'adolescence comme âge de la vie est définie, notamment dans les travaux d'Erik Erikson, comme une période d'hésitation identitaire amenant l'adolescent à interroger ce qu'il est, sur les plans sexuel et relationnel. Enfin, les théoriciens des industries culturelles et de la culture jeunesse tendent à mettre l'accent soit sur la dimension contestataire de « subcultures » en rébellion (Hall et Jefferson), soit sur l'invention de l'adolescent consommateur par les producteurs de contenu culturel et sur l'élaboration de codes spécifiques à son intention (Shary).

2. Les recherches de ces deux théoriciens consacrées au genre du teen movie mettent en avant la singularité générique d'un type de films qui, en dépit de leur diversité apparente, ont une cible commune : les adolescents.

3. Fondé en 1821, le Saturday Night Post est un magazine qui connut une très grande diffusion dans la première moitié $\mathrm{du} \mathrm{xx}^{\mathrm{e}}$ siècle et qui est associé aux valeurs de la classe moyenne américaine traditionnaliste.

\section{RÉSUMÉS}

L'article est consacré à la culture de jeunesse et aux productions littéraires et audiovisuelles destinées à la jeunesse. Il traite de la distinction entre les publics enfantins et adolescents dans la culture populaire contemporaine, envisagée à la fois du point de vue de la production et de la réception. L'article s'interroge sur les raisons de la confusion entre les catégories d'enfant et d'adolescent, et s'emploie à définir les critères possibles permettant de distinguer ces deux publics, en croisant psychologie, études culturelles et analyses internes des œuvres. L'enjeu est de délimiter le champ des productions culturelles ciblant spécifiquement un public adolescent, bien distinct, en dépit d'apparentes analogies, du public familial.

This paper deals with youth culture, focusing on literary, film, and television works. It examines the distinction between two types of audiences, namely children and teenagers, in contemporary popular culture, addressing both the production and reception of the works. It brings out the defining features which characterize these two audiences, through a multidisciplinary approach that pertains to psychology, cultural studies, and narratology. The purpose of this study is to delineate the field of youth culture by contrasting it with productions targeting family audiences. 
INDEX

Mots-clés : adolescence, cinéma pour adolescents, séries télévisées, double adresse, culture de jeunesse, jeune public, enfance, public familial, ciblage, réception

Keywords : adolescents and teenagers, teen movies, teens series, tweens, crosswriting, youth culture, young audience, childhood, family audience, targeting, reception

\section{AUTEUR}

ADRIENNE BOUTANG

Université de Franche-Comté, CRIT-IRCAV 